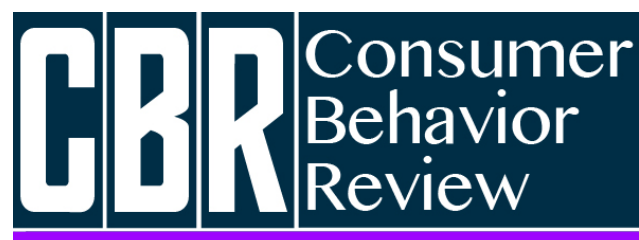

Revista Comportamento do Consumidor
Araujo, F. F., Turano, L. M., \& Vieira, F. C. (2019). Subculturas Religiosas de Consumo: Um estudo etnográfico de jovens católicos nas práticas dos Exercícios Espirituais. Consumer Behavior Review, 3(2), 99-119.
ISSN: 2526-7884

Editor: Prof. Dr. Marconi Freitas da Costa E-mail da revista: cbr@ufpe.br
Avaliação: Double blind review

Recebido: 22 de julho de 2019

Aceito 23 de setembro de 2019

\title{
SUBCULTURAS RELIGIOSAS DE CONSUMO: UM ESTUDO ETNOGRÁFICO DE JOVENS CATÓLICOS NAS PRÁTICAS DOS EXERCÍCIOS ESPIRITUAIS
}

\author{
Fábio Francisco de Araujo \\ Lucas Martins Turano \\ Fabrício Correia Vieira
}

Fábio Francisco de Araujo é Professor Adjunto de Gestão de Serviços da

Universidade Federal do Rio de Janeiro INJC/UFRJ. E-mail:

fabiofdearaujo@gmail.com.

Lucas Martins Turano é Mestre em Administração de Empresas pela Pontifícia Universidade Católica do Rio de Janeiro PUC-Rio. E-mail:

lucas.turano2@gmail.com.

Fabrício Correia Vieira é Graduação em Economia pela Pontifícia Universidade Católica do Rio de Janeiro - PUC-Rio. Email: vieira.fabricio.c@gmail.com.

Os autores agracedecem aos avaliadores pelos comentários para melhoria do artigo.

\begin{abstract}
Resumo
O objetivo da pesquisa foi identificar o impacto da religião nas escolhas de consumo, buscando compreender a influência dos significados atribuídos ao consumo na construção da identidade individual e coletiva desses jovens. Limitou-se a cultura de consumo católico a bens e atividades especificamente produzidos ou desenvolvidos para o consumo religioso, tais como retiros espirituais, objetos ritualísticos, objetos simbólicos e objetos de instrução, restringindo-se a análise e evitando impasses do ponto de vista epistemológico. Optou-se pelo método etnográfico da observação participante em retiro espiritual dedicado a prática dos Exercícios Espirituais desenvolvido por Santo Inácio, combinado com entrevistas em profundidade com os organizadores do evento e com alguns participantes. Os resultados apontam para quatro tendências principais identificadas: simbolismo e significado; construção e reforço da identidade; não consumo; e busca de interação. A pesquisa contribui para o conhecimento sobre as relações entre consumo e práticas religiosas, além de abrir novas perspectivas de pesquisa.
\end{abstract}

Palavras-chave: Comportamento do Consumidor, Práticas de Consumo Religioso, Identidades Sociais. 


\section{INTRODUÇÃO}

0 consumo tem sido compreendido nos últimos 30 anos como um elemento de construção, manutenção e modificação da identidade dos indivíduos (Holt, 2002). Como forma de estruturar sua identidade os indivíduos se valem de artifícios, tais como a criação de significado para os objetos que os cercam (Ahuvia, 2005). O consumo pode representar uma forma de distinção social em razão das identidades que são formadas, ou que se deseja formar, a partir dos hábitos de compra dos consumidores (Bourdieu, 1979). Os significados simbólicos atribuídos a determinados objetos são definidos pela sociedade na qual o consumidor está inserido, ou seja, os valores conferidos a esses objetos são compartilhados socialmente (Araujo \& Rocha, 2019).

Ao privilegiar, neste estudo, a dimensão simbólica do consumo religioso sob no contexto da mercadologia, não se pretende apresentar uma nova perspectiva, mas sim situar-se no corpo teórico de estudos em marketing que se apresenta como CCT - Consumer Culture Theory. Como já esclarecido por Arnould e Thompson (2005, p.868), as pesquisas na área de Consumer Culture Theory (CCT) em comportamento do consumidor não representam de uma perspectiva teórica única, mas pelo "contrário, refere-se a uma família de perspectivas teóricas que tratam dos relacionamentos dinâmicos entre as ações do consumidor, o mercado, e os significados culturais".

Nessa direção, cabe pontuar que o avanço nos estudos relacionados ao comportamento de consumo tem proporcionado o aprofundamento da disciplina nos últimos anos sob diferentes direções teóricas. Segundo Matsunobu (2018), o consumo religioso engloba tanto objetos quanto eventos considerados especiais em relação às atividades normais, sendo, portanto, tratados com algum grau de respeito ou reverência pelas pessoas. A compra de itens religiosos como chaveiros, camisas, livros, escapulários, pôsteres, cartões, bem como outros artigos ou atividades (eventos como: retiros, shows, peregrinações, cerimônias etc.) que apresentem relações com a fé humana têm crescido demasiadamente nos últimos anos (Araujo \& Tinoco, 2015). Destacam-se ainda alguns aspectos relevantes à análise, característicos da fé cristã já identificados em estudos anteriores, embora apresentem algumas peculiaridades para além da religião, entre elas: a relação com o passado estabelecida entre os praticantes; o caráter evangelístico dos seguidores cristãos; e a conexão com o seio familiar (Hirschman et al., 2010). Para Belk (1988), apreender o euestendido (extended self) é fundamental para se compreender como as posses individuais podem refletir na identidade e comportamento dos consumidores.

Esta pesquisa buscou analisar aspectos do comportamento de consumo de jovens da religião católica, investigando o impacto decorrente de pertencimento à religião a partir das práticas de consumo tanto para criação de significados dos bens consumidos quanto para construção de suas identidades. Para tal, utilizou-se um grupo de jovens integrantes da religião católica que participaram de um retiro religioso organizado por religiosos jesuítas. Optou-se por limitar a cultura de consumo católico a bens e atividades especificamente produzidos ou desenvolvidos para o consumo religioso, tais como retiros espirituais, objetos ritualísticos, objetos simbólicos e objetos de instrução, restringindo-se a análise e evitando impasses do ponto de vista epistemológico.

Tendo em vista a necessidade de um estudo mais aprofundado da história do consumo e diante da escassez de produções nesse âmbito, propõe-se um olhar contextualizado sobre as escolhas de compra deste grupo. Nesse contexto, o objetivo da pesquisa foi compreender o impacto da religião na criação de significado e na construção de identidade individual e coletiva por meio do consumo dos objetos ou eventos religiosos de jovens católicos. Pretende-se com esse estudo poder avançar no conhecimento sobre a influência de subculturas religiosas nas práticas de consumo, destacar a pertinência do tema e identificar pistas para as novas pesquisas.

\section{REFERENCIAL TEÓRICO Consumo e Cultura}

McCracken (1998) atribui ao consumo um importante papel no contexto social e cultural de uma comunidade. Segundo o autor, foi a partir do século XX que cultura e consumo criaram um vínculo inédito, uma vez que se 
percebe que a sociedade passa a absorver a sua cultura também por meio do consumo. Desse modo, a cultura fornece os padrões a partir dos quais as pessoas inseridas em um determinado grupo social irão afetar e interpretar o mundo a sua volta. De acordo com Appadurai (1990), a cultura pode ser representada por um conjunto de valores compartilhados por uma coletividade, o que promove a imposição de uma ordem de classificação, que é por natureza dispersa e heterogênea. Por sua vez, Baudrillard (1981, p.24) sublinha que a sociedade passou, nos últimos anos, a assimilar sua cultura por meio do consumo e, portanto, o consumo tornase "o modo como a sociedade se fala". Nesse sentido, o consumo assume significados que se manifestam nas relações coletivas, sociais ou grupais, ou seja, nas relações dos indivíduos uns com os outros.

Segundo Solomon (2011), o comportamento do consumidor pode significar uma afirmação sobre seu estilo de vida e sobre "quem é" ou quem "gostaria de ser". Entretanto, Rocha (2006) sinaliza que este debate é muito mais profundo, pois, segundo ele, a compreensão do termo "consumo" passa pela compreensão do que significa "cultura". Araujo e Rocha (2016) destacam que a conexão entre consumo e a cultura expressa uma das dimensões de uma sociedade. Em outras palavras, o consumo é assumido como parte da cultura de um determinado grupo social e, nesse sentido, a compreensão dos fenômenos relativos ao consumo reflete parte da compreensão dos fenômenos sociais, que é reproduzido em diferentes formas de expressão das relações entre os indivíduos (Araujo \& Chauvel, 2012). Camelo, Thomé e Junqueira (2018) pontuam que as influências nas escolhas dos consumidores são resultados dos valores socialmente compartilhados, que produzem e reproduzem comportamentos que são expressão do contexto cultural, ainda que este fenômeno não ocorra de modo consciente.

Nesse sentido, o consumo pode ser entendido como a transformação de produtos e serviços em um sistema de significados por meio do qual podem ser construídas facetas da subjetividade, que se traduzem em relações sociais e diversas necessidades simbólicas, emergindo como uma forma de interpretação do mundo que nos rodeia (Lin \& Dong, 2018). Dessa forma, o consumo pode representar com um verdadeiro código, o qual possui a propriedade de atribuir sentido a identidades, sentimentos e relações sociais (Rocha, 2006).

Na mesma direção, Ahuvia (2005) observa que o consumo de bens e serviços também é influenciado por sentimentos e relações sociais, uma vez que a trajetória de vida ou as influências mais recentes podem atribuir significados ao consumo. Em seu estudo, Ahuvia (2005) observou que os objetos de consumo são adquiridos por diferentes razões e dotados de significados individuais difíceis de serem transferidos. Observa-se, assim, que o significado do consumo pode não ser dado apenas pelos aspectos utilitários do bem ou do serviço, mas pode ser motivado pelo interesse particular de um indivíduo a partir de significados atribuídos por ele para a realização de uma prática de consumo específica. Dessa forma, tal prática de consumo não é inerente aos objetos, mas sim por quem os interpreta. Nesse sentido, Ahuvia (2005) defende que são os significados atribuídos a determinados produtos ou serviços que determinam o comportamento dos consumidores em relação a estes objetos de consumo.

\section{Consumo e Identidade}

Diversos autores se propuseram a estudar a relação entre consumo e formação de identidade, dentre eles Ahuvia (2005), Araujo et al. (2019), Belk (1988), Joseph e Southcott (2019), Holt (2002), Liechty et al. (2017), Picanço (2017), Silva-Lacerda (2016), entre outros. Esses estudos serviram como base para o entendimento do caráter simbólico do consumo, contribuindo para um maior aprofundamento sobre as motivações que impactam as decisões de compra. Bourdieu (1979) realizou um estudo que comparava o comportamento de consumo de pessoas de baixo capital cultural com o comportamento de consumo das pessoas de alto capital cultural na França. De acordo com os resultados da pesquisa, o autor observou que os indivíduos podem construir sua identidade a partir de hábitos e de aspirações de consumo. Inspirado por Bourdieu (1979), Holt (2002) avançou nesse debate empreendendo uma pesquisa similar no contexto norte-americano. Em sua pesquisa, Holt (2002) observou que os padrões de consumo somente poderiam ser 
compreendidos a partir das recompensas intrínsecas do ato de consumir, e não apenas a partir de uma ação estratégica ou por algum tipo de fomento instrumental para o consumo. Desse modo, o consumo se releva como forma de expressar aquilo que o indivíduo "é" ou "deseja ser", ou seja, o consumo funciona como um elemento de construção, manutenção e modificação da identidade dos indivíduos.

Refletindo sobre a influência do consumo sobre a formação da identidade dos indivíduos, Belk (1988) parte de conceitos da psicologia para desenvolver o conceito do eu-estendido (extended self). As contribuições de Belk (1988) ajudaram para uma maior compreensão do valor simbólico relacionados às posses e ao comportamento do consumidor. 0 eu-estendido aparece na relação entre os significados relacionados à posse de bens pessoais com a identidade do indivíduo. Dessa forma, pode-se depreender que os objetos configuram importantes elementos de formação de identidade dos indivíduos, já que estes objetos seriam capazes de expressar os gostos e interesses de seus possuidores e, por extensão, o seu eu (self).

Ao discutir sobre a construção da identidade na modernidade, Giddens (2002) pontua o consumo como componente integrante do estilo de vida escolhido pelo indivíduo. Segundo o autor, o contexto social pode influenciar as escolhas de consumo de diferentes maneiras. Estas influências ocorrem porque o indivíduo se mantém inserido em grupos diversos ao mesmo tempo, o que impacta em seu comportamento de consumo. Nesse contexto, é comum observar comportamentos de consumos movidos pela busca de aceitação social nos grupos dos quais participa, à medida que este busca uma espécie de estreitamento do laço de integração e identificação com o grupo.

Jenkins (2005) trabalha o tema sob outra ótica, na qual o principal fundamento é o de que a identidade pode ser formulada de maneira individual ou coletiva. Em ambos os modos, o processo de construção da identidade de um indivíduo se dá por meio de uma análise comparativa com pessoas e objetos, apesar de que, na primeira, são analisadas as diferenças que tornam os indivíduos singulares enquanto que a segunda maneira está baseada nas semelhanças dos indivíduos que pertencem ao grupo, possuindo um enfoque mais generalista.
Ahuvia (2005), partindo do pressuposto de que a identidade precisa ser construída de um modo ativo pelos indivíduos, introduz a ideia de que as pessoas se esforçam para configurar suas identidades. Ahuvia (2005) acrescenta ainda que objetos, experiências, grupos, crenças e outros elementos representam mais do que a dicotomia ser ou não self, podendo ser fortemente, parcialmente, ou não identificados com o self. Assim, diferentes objetos podem possuir diferentes níveis de atribuição, classificando-se de forma contínua.

Araujo e Tinoco (2015) realizaram uma pesquisa sobre as práticas de consumo de objetos religiosos por jovens judeus sublinham que o comportamento de consumo é marcado por uma forte influência familiar relacionada com a formação do indivíduo perante os valores da religião judaica, além de revelar a relação com o passado a partir da influência da história individual dos sujeitos. De outro lado, os objetos parecem guardar simbolismo e significados atribuídos de forma própria pelo consumidor, os quais demonstram que o consumo dos mesmos contribui diretamente para o reforço de suas identidades.

\section{Influências do Grupo de Referência no Consumo}

Conforme esclarece Solomon (2011), um grupo de referência pode ser tanto um grupo, quanto um indivíduo, fictício ou real, o qual possui a capacidade de ter significativa relevância sobre os indivíduos, inclusive no que diz respeito ao comportamento de consumo. "Nossas preferências são moldadas pelas nossas participações em grupos, pelo nosso desejo de agradar, de sermos aceitos ou até mesmo por pessoas que sequer conhecemos" (Solomon, 2011, p. 408). Segundo o autor, os grupos de referência são capazes de influenciar nas decisões de compra dos indivíduos de maneira informativa, utilitária e expressiva de valor.

Solomon (2011) sublinha ainda que o modo utilitário da influência dos grupos de referência sobre o comportamento do consumidor ocorre fundamentalmente para satisfazer as expectativas das pessoas com as quais 0 indivíduo interage socialmente. Peter e Olson (2009) complementam mencionando que a influência utilitária do grupo de referência controla recompensas e punições em relação a 
fazer ou não parte do grupo. Enquanto que a maneira informativa acrescenta que o indivíduo vai encontrar informações nos grupos de referência que influenciaram fortemente suas preferências de consumo. A influência expressiva de valor, mais relevante para este trabalho, ocorre quando o indivíduo realiza escolhas de consumo baseadas na crença de que o uso de certo produto gere respeito e admiração dos outros integrantes do grupo, promovendo sua imagem diante das pessoas e realçando características que ele possui ou gostaria de possuir (Solomon, 2011).

McFerran et al. (2010) empreenderam um estudo sobre influências no consumo em grupos de referência. Os pesquisadores realizaram três experimentos de um subgrupo formado por jovens de uma universidade norte-americana. Parte do experimento consistia na análise da influência que a obesidade de um indivíduo do subgrupo poderia exercer no consumo de alimentos dos demais. Para realizar o experimento, uma jovem assistente de pesquisa, considerada a âncora para referência de consumo, foi infiltrada entre os participantes e se apresentava com dois biótipos corporais diferentes, um magro (seu biótipo normal) e outro obeso (biótipo obtido por meio de próteses), consumindo em ambos os casos um nível elevado de alimentos. 0 resultado foi que houve uma redução na média de alimentos consumidos pelos integrantes do grupo quando a âncora se apresentava com o biótipo obeso do que quando a âncora se apresentava com o biótipo magro. Segundo os pesquisadores, os resultados do estudo mostram que existe uma preocupação em manter um biótipo aparentemente saudável.

Schouten e McAlexander (1995) realizaram uma pesquisa etnográfica sobre um subgrupo de motociclistas, observando a influência do grupo de referência nas práticas de consumo de seus membros. Os autores analisaram um subgrupo de proprietários de motocicletas Harley-Davidson, conhecidos como Harley Owners Group (HOG). Segundo os autores, os membros do grupo gastam uma boa quantia em dinheiro com vestuário e acessórios para motocicletas e também para si, com evidentes valores simbólicos de integração ao grupo no qual está inserido. Alguns membros do HOG se sentem tão embrenhados neste sentimento de irmandade proveniente de seu grupo de referência que consomem tatuagens com o nome da marca, sinalizando aos demais integrantes um estilo de vida e comportamento fortemente valorizado no subgrupo, além da atribuição de grande valor ao pertencimento do grupo.

Nesse sentido, os grupos de referência se mostram uma importante fonte de influência no comportamento do consumo. Como destacado por McFerran et al. (2010) alguns indivíduos possuem maior influência nas decisões de consumo dos outros, sobretudo quando um indivíduo ajuda a reforçar padrões de conduta dentro do grupo de referência mais do que outros integrantes, o que Solomon (2011) pontua como influência normativa. Schouten e McAlexander (1995) observam, por meio do exemplo do HOG, que um grupo de referência pode afetar as decisões relativas a marcas, a produtos, a serviços, e até em outras atividades específicas, como a decisão de participar ou não de grupos fechados como determinados tipos de clubes, ao que Solomon (2011) classifica como fenômeno da influência comparativa.

\section{Impactos da Religião nas Práticas de Consumo}

As diferentes subculturas religiosas impactam fortemente nas decisões dos indivíduos (Solomon, 2011), o que impulsiona diferentes formas de necessidades, tais como a formação de identidade (Hirschman et al., 2010; Mansori, 2012; Wallendor \& Reilly, 1984). Os diferentes grupos religiosos estão muito atrelados aos aspectos culturais (Hirschman et al. 2010), o que também reforça o apelo para construção de uma identidade coletiva por pessoas que partilham uma mesma cultura (Jenkins, 2005).

Nesse sentido, a relação com o passado se mostra um elemento importante na compreensão das influências das identidades dos atores. Para Belk (1988), alguns objetos têm a capacidade simbólica de fazer com que o indivíduo se remeta a experiências ocorridas no passado, segundo o autor, enquanto novas experiências estão sendo formadas, memórias de experiências passadas são ao mesmo tempo mantidas e reafirmadas. Ahuvia (2005), na mesma direção, acrescenta a importância das narrativas de vida das pessoas, pois o autor observou, em sua pesquisa, que os 
entrevistados articulavam sua relação com objetos especiais de consumo com suas trajetórias de vida e com suas recentes experiências pessoais.

Sustenta-se, desse modo, a grande importância do consumo ao longo do tempo como forma de sustentação da tradição, dada pela importância atribuída a alguns objetos. Assim, os indivíduos podem optar por consumir alguns tipos de objetos ou algumas atividades religiosas que o ajudam a mostrar o tamanho da intensidade e do comprometimento com a religiosidade praticada, além de servir como uma ferramenta capaz de reforçar suas crenças, valores e significados (Minkler \& Cosgel, 2004). De acordo com Minkler e Cosgel (2004), esse reforço constante de crença alimentado por meio de objetos e práticas ligadas a ritualística entre os membros da religião é um elemento fundamental para construção da identidade religiosa coletiva. Solomon (2011) também complementa essa discussão colocando que as subculturas religiosas exercem intensa influência sobre as decisões de consumo dos indivíduos. Segundo o autor, o consumidor pode ser influenciado em diferentes aspectos, entre os quais estão a personalidade individual, atitudes políticas e formação de lares.

Solomon (2011, p. 531) ressalta ainda que os líderes religiosos possuem um grande poder de influência e, portanto, conseguem estimular favoravelmente um determinado comportamento de consumo ou, em sentido contrário, conseguem desencorajá-lo conforme as crenças e os valores compartilhados pelos participantes da religião. No mesmo sentido, Klein e Laczniak (2009), em um estudo que discute a ética nas estratégias de marketing e as responsabilidades do consumidor católico em relação a sua participação no mercado de consumo, militam no sentido que o católico deve sempre observar os valores sociais da Igreja para exercer o seu papel de consumidor de forma condizente com os princípios defendidos pela religião em que está inserido. Os autores destacam que os consumidores católicos devem realizar escolhas de consumo que atendam às necessidades autênticas enquanto devem evitar produtos, comportamentos e estilos de vida que podem se colocar em perigo ou explorar os outros. Além disso, Klein e Laczniak (2009) colocam que os consumidores católicos devem priorizar produtos e serviços que tenham compromisso com a sustentabilidade, visando à obtenção de um melhor bem-estar para as gerações futuras.

Silveira (2011), em seu estudo sobre eventos festivos englobados na cultura católica, ressalta a produção de um novo significado religioso para práticas festivas. Segundo o autor, a religião é fortemente influenciada pela cultura moderna. Em sua pesquisa, Silveira (2011) observou uma espécie de ressignificação de fatores culturais por aspectos divinos, permitindo compreender alguns comportamentos de consumo religioso sobre outra ótica. 0 pesquisador relaciona o consumo de atividades festivas aos valores presentes na contemporaneidade cultural, recaindo principalmente sobre os membros que possuem maior necessidade de usufruir de prazeres modernos e de reconstruir um novo tipo de identidade sem perder o caráter divino. Os ritos festivos por ele mencionados reafirmam o vínculo social e cultural entre os membros do subgrupo, exaltando a tradição religiosa reformulada pelo modernismo e reforçando a identidade religiosa dos indivíduos.

\section{METODOLOGIA}

A perspectiva do artigo se insere dentro de um paradigma interpretativista, filiando-se área de pesquisa denominada Consumer Culture Theory (CCT) em comportamento do consumidor (Arnould e Thompson, 2005), tendo em vista que o estudo se dedica em compreender os chamados relacionamentos dinâmicos entre as ações do consumidor e os significados culturais. Nesse sentido, a linha de investigação proporcionada pela área de pesquisa da Consumer Culture Theory (CCT) contribuir para interpretar como os indivíduos interagem e constroem significados no contexto cultural em que estes se inserem, buscando traduzir a realidade construída pelos sujeitos a partir de suas práticas de consumo.

Segundo Hirschman e Holbrook (1992), na obra que escreveram sobre a pesquisa do consumidor pós-moderno, o paradigma interpretativista, em comportamento do consumidor, é adequado para compreender como o indivíduo interage e constrói significados com objetos externos, buscando traduzir a realidade construída pelos sujeitos. Lincoln e Guba (1985) ensinam que o 
paradigma interpretativista é útil para pesquisas que buscam por compreender as relações dinâmicas entre as ações dos consumidores, o mercado e os significados culturais. Optou-se pela construção do entendimento da realidade a partir da narrativa dos entrevistados. Nesse sentido, a abordagem hermenêutica é apropriada para condução do presente estudo (Thompson, 1997).

0 método escolhido para a pesquisa foi o de "inspiração etnográfica" (Elliot \& Jankel-Elliot, 2003). De acordo com Vergara e Caldas (2005), este método se caracteriza pelo estudo detalhado do cotidiano da vida das pessoas que estão imersas no fenômeno. 0 método etnográfico é representado pelo uso de técnicas de observação, que se caracteriza no fato de ingressar em determinado grupo social e observar as atividades desenvolvidas pelos indivíduos pesquisados. A técnica de observação demonstrou ser um recurso bastante útil para investigações e estudos em administração, até mesmo quando não acompanhada pela etnografia (Tureta \& Alcadipani, 2011). Arnould e Wallendorf (1994) ensinam que existem quatro características que distinguem os estudos etnográficos: (1) coleta sistemática de dados em ambiente natural; (2) participação experiencial do pesquisador no contexto cultural em questão, notadamente via observação participante; (3) interpretações críveis dos mecanismos culturais em questão, os quais restam normalmente desarticulados pelos participantes no dia a dia; (4) múltiplas fontes de dados, de modo a captar perspectivas variadas acerca dos contextos de interesse.

Elliot e Jankel-Elliot (2003), sublinham que o método etnográfico e o uso das técnicas que o compreendem, recebem adaptações que tornaram possível sua utilização na disciplina de marketing. Esse procedimento foi necessário em função da dinâmica própria que envolve a realidade da disciplina, como, por exemplo, a necessidade de repensar o tempo e as formas de imersão no campo para coleta de dados. Por esta razão, considerando que este estudo não foi conduzido por pesquisadores de antropologia, mas sim conduzido por pesquisadores da área de administração, optou-se por classificar o estudo como de "inspiração etnográfica". Optouse por realizar uma "pesquisa infiltrada" (Tureta \& Alcadipani, 2011, p. 213), na qual o pesquisador pode assumir não revelar os seus propósitos de pesquisa durante a inserção no grupo estudado, evitando que a informação dos interesses da pesquisa pudesse retirar a espontaneidade dos participantes para com os pesquisadores, bem como influenciar o comportamento dos pesquisados e, assim, podendo gerar vieses nos resultados do estudo.

Segundo Barros (2009), os estudos etnográficos sobre consumo produzidos na área acadêmica de marketing têm permitido maior proximidade com o modo de pensar do consumidor. Conhecer o comportamento de compra, de que forma consomem, como os grupos se classificam em relação a outros grupos a partir do uso de determinados produtos, são alguns exemplos de descobertas que podem ser aprofundadas a partir da aplicação desta opção metodológica. Na pesquisa etnográfica, o comportamento humano é compreendido a partir de uma visão mais ampla da vida em sociedade, o que Barros (2009, p.104) chamou de "processo simbólico cultural".

Nesse contexto, por meio da observação participante e da realização de entrevistas em profundidade, a etnografia viabiliza o alcance de um entendimento mais profundo sobre um fenômeno investigado, desvelando sua subjetividade e singularidade dentro de um elenco de fenômenos sociais. Segundo Sahlins (1978), o comportamento humano é um ato simbólico, cultural e coletivo. Segundo Geetz (1978, p. 24), tais descobertas seriam expressas por meio de um relato profundo da cultura relativa ao fenômeno social analisado, chamada por Geetz de "descrição densa das estruturas significantes".

Nesta pesquisa, a observação participante foi realizada em um retiro católico para jovens com a duração de quatro dias, organizados por católicos da espiritualidade inaciana com apoio de religiosos jesuítas, ocorrido na cidade do Rio de Janeiro por quatro dias. 0 evento era aberto para jovens com idades entre 15 a 35 anos. A coleta de dados foi realizada por intermédio de entrevistas informais com os jovens participantes, pela observação e interação com a dinâmica do evento. Além disso, foram feitas fotografias para auxiliar a etapa de análise de dados. As entrevistas informais com os jovens ocorreram durante o retiro, sendo conduzidas por meio de perguntas abertas mais gerais sobre o fenômeno em análise e outras mais 
específicas construídas a partir da própria experiência trazida pelos informantes durante a entrevista. 0 conteúdo da observação e das entrevistas informais foi registrado no diário de campo dos pesquisadores (Oliveira, 2006). Considerando se tratar de um retiro de silêncio, foi necessário que essas interações com os participantes fossem autorizadas, tendo sido orientado que ocorressem de forma breve em momentos de intervalo após o almoço nos diferentes dias do retiro. Ao todo, foram realizadas doze entrevistas informais com jovens participantes, que tiveram duração de 20 a 25 minutos.

Optou-se, ainda, pela realização de entrevistas em profundidade para coletar dados que fornecessem subsídios e suporte para o que foi evidenciado na experiência do evento religioso. Seidman (2006) sublinha que o objetivo de uma entrevista em profundidade é entender a experiência vivida pelo informante para compreender os significados atribuídos a ela. Para realização das entrevistas em profundidade, foi elaborado um roteiro de entrevista semiestruturado com perguntas abertas sobre o fenômeno em analisado.

As entrevistas foram realizadas com três pessoas que colaboraram para realização do retiro, um padre jesuíta, um irmão jesuíta e uma funcionária da pastoral da universidade católica que promoveu o retiro. 0 tempo de entrevista durou entre 50 minutos e 1 hora e 20 minutos. Elas foram integralmente gravadas e transcritas para análise. As entrevistas tiveram como principal objetivo o auxílio no entendimento das motivações dos organizadores que prepararam o retiro, cotejando-os com as motivações informadas pelos participantes entrevistados. Todos os dados colhidos foram analisados conjuntamente, buscando-se compreender o significado do consumo de produtos e eventos religiosos pelos jovens que participaram desta atividade religiosa.

A análise de dados seguiu a técnica da análise de conteúdo (Bardin, 2011). Considerando o objetivo delimitado, iniciou o processo de análise dos significados atribuídos ao consumo dos objetos religiosos. A escolha de documentos que constituíram o corpus se deu por meio análise da narrativa dos informantes em função de um recorte a partir dos discursos em relação ao fenômeno em análise, selecionados no diário de campo nas observações dos pesquisadores e conversas informais, nas fotografias registradas e das transcrições das entrevistas em profundida com os organizadores do evento. Essa análise preliminar seguiu o método interpretativo da hermenêutica (Ahuvia, 2005; Thompson, 1997), o que levou à preparação do material para uma análise interpretativa mais profunda e refinada do conteúdo selecionado.

Em seguida, conforme procedimento indicado por Strauss e Corbin (2008), a análise do conteúdo foi se processando da seguinte maneira: desenvolvimento de um conjunto de categorias e temas iniciais; identificação nos diários de campo e nas transcrições de entrevistas de partes descritas no discurso dos informantes correspondentes àquelas categorias; identificação de novas categorias e temas que emergiram do campo; reagrupamento de categorias e temas; nova leitura do diário de campo e das transcrições, incluindo retornos constantes à teoria para cotejar com o resultado das categorias e temas reagrupados; seleção de novos trechos dos discursos dos informantes ou novos trechos dos registros do diário de campo correspondentes às novas categorias para confirmação das categorias emergentes dos dados analisados.

Pelo caráter exploratório da pesquisa, não há intenção de generalização ou de extrapolação, busca-se com esta pesquisa contribuir ao avanço do conhecimento do tema e trazer subsídios a futuras pesquisas a partir de diferentes perspectivas sobre a temática do comportamento do consumidor.

\section{ANÁLISE DOS RESULTADOS}

0 objetivo da pesquisa foi compreender o impacto da religião na criação de significado e na construção de identidade individual e coletiva por meio do consumo dos objetos ou eventos religiosos de jovens católicos. Os dados obtidos indicaram que entre os jovens entrevistados não há unanimidade para o consumo de objetos ou eventos religiosos. Poderia se esperar que, dada a faixa etária, a motivação para o consumo do retiro espiritual fosse relativamente similar, contudo as motivações expressas pelos jovens se revelaram heterogêneas. Entretanto, esses resultados vão ao encontro do que foram observados nos estudos de Belk (1988) e Ahuvia (2005), que 
abordam sobre a personificação dos objetos de consumo de acordo com a percepção do "eu" dos indivíduos, o que tende a variar de indivíduo para indivíduo. De outro lado, pesquisadores têm observado que o comportamento do consumidor e sua relação com a religião ocorrem por meio de estratégias específicas desenvolvidas pelos consumidores a partir de seus valores, suas práticas de lazer, sua cultura e sua tradição religiosa (Breheny \& Stephens, 2017; Hirschman et al., 2010; Iwasaki, 2017; Mansori, 2012; Matsunobu, 2018; Ryu \& Heo, 2018).

O retiro foi realizado no feriado de Corpus Christi, iniciando-se na quinta-feira e concluindo-se no domingo após o almoço. 0 evento foi realizado na Casa de Retiros Anchieta, no bairro de São Conrado, na cidade do Rio de Janeiro, tendo sido organizado por uma universidade católica localizada próxima à casa de retiros. Tratou-se de retiro conduzido por religiosos jesuítas, intitulado Exercícios Espirituais para Jovens (EEJ), direcionados a jovens interessados em praticar os exercícios espirituais desenvolvido por Santo Inácio de Loyola. Os organizadores do retiro limitaram a inscrição para jovens com idades entre 15 a 35 anos.

Esse evento foi criado em São Paulo, em um centro de juventude. Eles começaram a aplicar por lá, pensando como fazer os exercícios por lá, de uma forma mais acessível à juventude... Primeiramente, nós temos interesse que os jovens possam ter acesso aos exercícios espirituais de Santo Inácio... Os exercícios são coisas para cristãos que querem aprender a rezar e ter uma relação com Deus. Então, como fazer isso chegar à juventude?... Então, a forma de aplicar os exercícios foi adaptada para os jovens. (Padre Jesuíta em entrevista aos autores).

De acordo com os organizadores do evento, a proposta do evento foi ajudar os jovens a sentir, por meio da oração, uma experiência com a espiritualidade inaciana, proposta pelos exercícios espirituais. Os organizadores do evento defendem que a experiência pode ajudálos a crescer em sua espiritualidade, desenvolverem-se mais na virtude no seu contexto pessoal, além de abrir espaço para reflexões sobre a possibilidade de realizações concretas do ambiente religioso ou social. Nas palavras dos entrevistados:

Geralmente eles se surpreendem quando eles chegam. [...] 0 exercício é silêncio! Então, primeiramente, há uma surpresa! Depois, em seguida, eu acho que eles buscam um pouco de interioridade. É uma busca de virtude. 0 mundo está muito agitado. Então, a juventude quer um caminho de descanso, um caminho de repouso, repouso espiritual também [...] (Padre Jesuíta em entrevista aos autores).

Eu vejo que aqueles que fizeram e estão buscando fazer os exercícios espirituais, estão buscando alguma coisa na sua vida concreta. E, é isso, eu acho que não só buscando um sentido, mas aquilo que eles podem realizar [...]. Aquilo que eles podem fazer mesmo na sua realidade, na sua comunidade, no seu contexto... (Funcionária da pastoral universitária em entrevista aos autores).

Além de discutir sobre as motivações para o consumo do retiro pelos jovens, os entrevistados forneceram informações sobre outras formas de consumo entre jovens participantes. Geralmente, no espaço do retiro não são estimuladas outras espécies de consumo, ainda assim os organizadores observaram que estes jovens estão interessados em adquirir objetos ou atividades relacionadas à fé praticada.

\section{Vários dos que vêm fazer os exercícios já vêm [...] com os seus kits espiritualidades [...] Camiseta é o principal deles. [...] eventualmente nós promovemos algo assim também, nós temos umas fitinhas de braço que a gente gosta de distribuir também como material de uma certa lembrança e divulgação da espiritualidade. São fitinhas que têm uma frase de Santo Inácio e tal, que ajuda a vincular com a experiência. Você lê aquela frase e lembra daquela experiência vivida, aquilo te ajuda. (Irmão Jesuíta em entrevista aos autores).}

Para a funcionária da pastoral universitária que ajudou na organização do evento, alguns desses objetos são relacionados com o desejo de mostrar sua inserção em um grupo, para pontuar sua crença e seu pertencimento a um grupo. 
Autoafirmar-se. De identificar, de mostrar: 'olha, eu gosto desse grupo, sou fã, eu apoio'. Mas, eu acho que na linha dos jovens religiosos católicos é pulseira, terço [...] isso é porque é testemunho, é identificação, é mostrar que eu pertenço a esse grupo, eu acredito nisso. (Funcionária da pastoral universitária em entrevista aos autores).

Essa reflexão sugere que os jovens buscam afirmar sua identidade escolhida por meio do objeto de consumo, o que remete as contrições de Jenkins (2005) sobre como a identidade social é construído num constante esforço de ser e se tornar. Nesse contexto, as posses religiosas adquiridas podem ser compreendidas por parte de seu eu-estendido (Belk, 1988), representando objetos especiais para si em função de identificar pertencimento e valores espirituais.

Na visão do Padre Jesuíta que colaborou com a organização dessa edição do EEJ, além disso, o comportamento de consumo desses jovens em relação aos objetos e eventos religiosos está relacionado a um significado profundo de sua fé.
Algumas práticas de consumo passam por rituais ligadas a espiritualidade do jovem, como o próprio retiro, bíblia, imagens, terços etc. Enquanto outras formas de consumo, como camisas e fitinhas, por exemplo, podem estar relacionadas com identificação e pertencimento.

[...] quando eles compram terço, isso também é bênção. 0 terço, do ponto de vista espiritual, né? Quando eles compram uma imagem, eles certamente pensam na imagem. Então imagens, geralmente, são ritos espirituais, terços também. Cordão, nem sempre. Alguns, sim. Camisa nunca, eu acho. (Padre Jesuíta em entrevista aos autores).

Ao longo do retiro, os pesquisadores interagiram individualmente com alguns dos jovens participantes. Foram realizadas entrevistas informais com doze desses jovens, com idades entre 17 e 33 anos. Com o intuito de preservar suas identidades, os nomes dos participantes foram alterados e seus perfis são descritos no quadro a seguir:

\begin{tabular}{|c|c|c|c|c|}
\hline Entrevistado & Idade & Sexo & Motivo para ida ao evento & Consumo Religioso Mencionado \\
\hline Airton & 22 & Masc. & $\begin{array}{l}\text { Desenvolver espiritualidade e } \\
\text { como teste vocacional }\end{array}$ & $\begin{array}{c}\text { Escapulários, fitinhas, camisas, } \\
\text { livros e tatuagem }\end{array}$ \\
\hline Carla & 23 & Fem. & Desenvolver espiritualidade & $\begin{array}{c}\text { Livros, terços, camisas, eventos } \\
\text { religiosos }\end{array}$ \\
\hline Cristina & 26 & Fem. & $\begin{array}{c}\text { Afastamento do estresse urbano e } \\
\text { desenvolver espiritualidade }\end{array}$ & $\begin{array}{c}\text { Livros, DVDs de Yoga, eventos e } \\
\text { músicas religiosas }\end{array}$ \\
\hline Déia & 23 & Fem. & Desenvolver espiritualidade & Músicas, livros, retiros religiosos \\
\hline Hudson & 25 & Masc. & $\begin{array}{c}\text { Desenvolver espiritualidade e } \\
\text { servir a Deus }\end{array}$ & $\begin{array}{c}\text { Fitinhas, livros, terços, eventos } \\
\text { religiosos }\end{array}$ \\
\hline Isabela & 21 & Fem. & $\begin{array}{c}\text { Desenvolver espiritualidade e } \\
\text { praticar a língua portuguesa }\end{array}$ & Escapulários, livros \\
\hline João & 28 & Masc. & $\begin{array}{c}\text { Desenvolver espiritualidade e } \\
\text { aprender as dinâmicas dos } \\
\text { exercícios espirituais }\end{array}$ & Livros, Eventos e escapulários \\
\hline Kelly & 32 & Fem. & $\begin{array}{c}\text { Desenvolver espiritualidade, } \\
\text { novas amizades, buscar } \\
\text { crescimento na relação com Deus } \\
\text { e com próximo }\end{array}$ & Livros, cursos e eventos religiosos \\
\hline Leonardo & 26 & Masc. & $\begin{array}{l}\text { Novas Amizades e desenvolver } \\
\text { espiritualidade }\end{array}$ & Livros, camisas, músicas e DVD \\
\hline Tácio & 17 & Masc. & $\begin{array}{c}\text { Desenvolver espiritualidade e } \\
\text { buscar a reflexão interna por } \\
\text { meio do silêncio }\end{array}$ & $\begin{array}{c}\text { Bíblia, missal, livros de instrução, } \\
\text { estuda latim com fins religiosos, } \\
\text { santos, cruzes, escapulários, } \\
\text { eventos religiosos como retiros e } \\
\text { passeios } \\
\end{array}$ \\
\hline Tales & 33 & Masc. & $\begin{array}{l}\text { Desenvolver espiritualidade, } \\
\text { buscar crescimento na relação }\end{array}$ & $\begin{array}{l}\text { Livros, escapulário, DVDs, eventos } \\
\text { religiosos, e outros objetos }\end{array}$ \\
\hline
\end{tabular}




\begin{tabular}{|c|c|c|c|c|}
\hline & & & $\begin{array}{c}\text { com Deus e com próximo, e } \\
\text { buscar discernimento para } \\
\text { exercer uma atividade religiosa }\end{array}$ & $\begin{array}{c}\text { religiosos (para si e para } \\
\text { presente), filmes religiosos, } \\
\text { viagens religiosas }\end{array}$ \\
\hline Walter & 25 & Masc. & $\begin{array}{l}\text { Desenvolver espiritualidade e } \\
\text { aprender as dinâmicas dos } \\
\text { exercícios espirituais }\end{array}$ & Livros, eventos e um crucifixo \\
\hline
\end{tabular}

Fonte: Elaboração dos autores.

Quadro 1: Perfil dos informantes

0 quadro 1 apresenta cinco informantes do sexo feminino e sete do sexo masculino, os quais apresentam consumos variados, destacando-se, porém, algumas similaridades que serão apresentadas nos resultados de pesquisa. Observou-se também que houve unanimidade no sentido de que todos os jovens informantes entendem o retiro como algo que lhes proporcionaria o desenvolvimento de suas espiritualidades.

As observações realizadas neste estudo a partir das entrevistas com os jovens participantes do EEJ permitiram formar quatro diferentes categorias de análise, a saber: (1) simbolismo e significados; (2) não consumo; (3) busca de interação; (4) construção e reforço da identidade.

\section{Simbolismo e Significados}

A tentativa de manter a tradição religiosa remonta a discussão feita no estudo de Hirschman et al. (2010), o qual destaca que a religião suscita sobre os indivíduos um acesso ao um universo simbólico, carregado de significado. Para Bourdieu (2004), a religião pode ser entendida como um dos sistemas simbólicos que permeiam a existência, em que a transformação do mito em ideologia não se separa da construção de um corpo especializado de produtores de discursos. Dotson e Hyatt (2000) defendem que religião também pode ser interpretada como uma cultura que possui o papel de transformar o místico em algo com um significado às pessoas, dando-lhes acesso a um mistério considerado sagrado. Nesse contexto, constatou-se que os informantes desta pesquisa foram unânimes em declarar que a motivação de consumir o retiro passava pelo desenvolvimento da espiritualidade, associando-a ao valor simbólico atribuída ao retiro, como possibilidade de oração, interação com Deus e com pessoas que compartilham os mesmos interesses, e além da possibilidade de crescimento.
A proposta de silêncio foi compreendida, por alguns, como um meio de se sentir mais intensamente a experiência, e assim poder se aproximar de Deus observando a pulsão da vida por meio do outro, da natureza e do próprio pensamento. Para o jovem entrevistado Hudson, a religião o ajuda a ser mais consciente em relação ao mundo, tornando-o um homem mais reflexivo. Por sua vez, Tácio comentou que o silêncio contribuiu muito para suas reflexões sobre a vida e sobre Deus. Outra informação interessante foi à busca dos participantes deste retiro por objetos que permitam que eles se aprofundem nos valores religiosos. Grande parte dos informantes desta pesquisa citou livros religiosos como objeto de consumo, o que sugere a importância do reforço e da imersão nos significados religiosos.

Airton, Carla, Leonardo e Walter mencionaram também consumirem objetos que demonstrem a participação e a vivência em grupo de subculturas católicas, como camisas de eventos, atividades paroquiais ou de símbolos católicos. Airton revelou que consome camisas religiosas com frases de impactos, remetendo a um significado que vai além da ideia do católico ativo, mas que também expresse personalidade forte. 0 caso do Airton avança no debate proposto por Silveira (2011), que identificou em sua pesquisa a questão da resignificação de fatores culturais da modernidade relacionando com aspectos divinos, como no caso deste jovem, que informou procurar vivenciar o rock de maneira interligada com a sua religião.

Déia, Tácio e Tales destacaram entre seus itens religiosos consumidos, exemplos que simbolizam formas de consumo hedônico. Déia tem por hábito consumir partituras de músicas religiosas e apresentações de música sacra como forma de buscar bem-estar e as possíveis realizações de fantasias (Holbrook \& Hirschman, 1982), que suscitam suas emoções e sentimentos. Para a informante, esta forma de consumo simboliza também um meio de 
experiência mais íntima com a fé praticada. No mesmo âmbito, Tácio estuda latim por ser a língua oficial do Vaticano em busca de uma aproximação da essência ritualística católica, valorizando suas crenças por meio do esforço para aspiração aos ensinamentos que balizam a sua fé. Essa escolha de consumo do entrevistado remete a uma forma de esforço para manter a tradição, conforme identificado no estudo de Hirschman et al. (2010).

Seguindo a mesma linha, Tales inclui entre seus itens consumidos viagens de motivação religiosas, como a Peregrinação de Santiago de Compostela, também simbolizando a experiência do consumo ligado aos significados religiosos inerentes de sua fé. 0 consumo da viagem mencionado por Tales pode ser relacionado com as chamadas experiências hedônicas (Guido et al., 2007), que envolve atributos emocionais e multissensoriais das escolhas de consumo. Brakus et al. (2009) aprofundam o debate sobre as experiências hedônicas de consumo que os estímulos recebidos para motivação são partes da experiência e constituem a maior fonte de respostas subjetivas do consumidor, o que no caso de uma viagem religiosa é relacionado às crenças e aos significados valorizados pelo consumidor.

Entre os entrevistados, verificou-se que o consumo por eventos religiosos é fortemente valorizado, o que pode estar relacionado ao "significado" que os próprios informantes atribuíram ao retiro católico, como a oportunidade de parar e sair do cotidiano para se relacionar com Deus. Kelly, por exemplo, identificou-se como espírita kardecista e informou participar do retiro por gostar da proposta e por considerar que as religiões estão interligadas. Ela atribui ao retiro católico um significado de aproximação com Deus e de aproximação de pessoas com aspirações espirituais semelhantes às dela. Cristina, que informou ser ateia antes do retiro, mencionou que decidiu participar da atividade com intuito de conhecer melhor as religiões, tendo passado a crer em Deus durante o retiro devido a experiências vivenciadas no evento. Já Leonardo, que também se identificou como espírita kardecista, atribuiu ao retiro um significado de fazer novas amizades espiritualizadas.
Para Isabela, estudante espanhola em intercâmbio em uma universidade católica do Rio de Janeiro, o evento significou uma oportunidade o desenvolvimento de sua espiritualidade católica com jovens de outro país, além de uma oportunidade de praticar a língua portuguesa no contexto religioso. A tentativa de manter a tradição religiosa mesmo vivendo em um país estrangeiro remonta a discussão feita por Wallendorf e Reilly (1983). Apesar de estar realizando um intercâmbio acadêmico, a participante vislumbrou na atividade do retiro a possibilidade de conhecer e interagir com pessoas que professam a mesma fé e assim partilhar a experiência. Além disso, as motivações de Isabella passam pela sociabilidade espontânea com pessoas que possuem a mesma religião e que contribuem para um melhor entrosamento e adaptabilidade ao mundo da vida de que fala Habermas (2004).

Como observado durante as entrevistas, João e Walter revelaram que o retiro tem significado de formação. Ambos os jovens possuem papel muito ativo em suas comunidades em relação à Igreja. João trabalha em sua paróquia, exercendo liderança no grupo jovem e ministrando cursos de formação para esse grupo. Assim, ele informou que o retiro seria uma oportunidade de se fortalecer espiritualmente e aprender práticas religiosas que podem ser replicadas em sua paróquia. No mesmo sentido, Walter informou ser ativo em sua paróquia e participar de grupos ligados a juventude católica, destacando que fez o retiro para desenvolver mais espiritualidade e aprender mais sobre a espiritualidade de Santo Inácio e também sobre as dinâmicas dos exercícios espirituais para eventualmente replicá-los em sua comunidade.

\section{Não Consumo}

Se de um lado a religião pode encorajar o consumo, por outra via pode desencorajá-la (Solomon, 2011), o que gera comportamentos de não consumo. Os jovens entrevistados nesta pesquisa destacaram a opção pelo não consumo ou, em alguns casos, a busca de um comportamento de consumo moderado, buscando estabelecer um equilíbrio com os valores religiosos. Isabela comentou que os valores desenvolvidos por influência da religião ajudaram a buscar um consumo mais 
consciente, evitando o excesso. Ahuvia (2008), no estudo em que investigou se o dinheiro pode "fazer" felicidade, verificou que alguns consumidores começaram hoje a se questionar, percebendo que o consumismo e o materialismo não levam necessariamente à felicidade, ao contrário pode até reduzir o bem-estar dos indivíduos. Por sua vez, Klein e Laczniak (2009) defendem que os consumidores católicos devem buscar atender necessidades autênticas no mercado de consumo, evitando o desperdício ou comportamentos de consumo não planejados, desnecessários ou injustos.

A opção de não consumo pode ser motivada pelos valores religiosos (Solomon, 2011) ou por influência dos grupos de referências (McFerran et al., 2010; Peter \& Olson, 2009). Um Grupo de pessoas que partilham uma mesma religião pode ser considerado um grupo de referência (Solomon, 2011), enquanto pessoas de mesma faixa etária que partilham uma mesma situação ou convivem em um mesmo grupo podem influenciar o consumo uns dos outros (McFerran et al., 2010). 0 efeito do grupo de referência contribuiu para a opção de não consumo de alguns jovens entrevistados em relação às bebidas alcoólicas e cigarros. Hudson, Isabela, Tácio e Tales afirmaram não fumar por acreditarem não ser um bom exemplo de jovens praticantes da fé cristã, o que pode ser relacionada a influência expressiva de valor que os grupo de referência podem gerar (Solomon, 2011, p. 409), no qual o indivíduo acredita que consumo influencia na imagem que os outros têm dele. No mesmo sentido, os três rapazes afirmaram não beber, enquanto Isabela defende que o consumo de bebidas alcoólicas deve ocorrer com moderação para evitar o mau testemunho para os não praticantes da religião.

0 não consumo de droga também foi mencionado por alguns jovens. Hudson comentou que os valores religiosos foram fundamentais para recusar o consumo de drogas em festas de jovens durante sua juventude. Tácio e Tales informaram também que a prática da religião os motivaram a não conhecer as drogas. Enquanto Walter assumiu ter consumido drogas e, em seu caso, a religião serviu de apoio para deixar a prática desse tipo de consumo.

Tácio destacou que evita consumo coisas que não ajudam crescer espiritualmente, incluindo, além dos comportamentos de não consumo já mencionados, farras, materiais pornográficos e livros que criticam ou se opõe às práticas da fé católica. No mesmo sentido, Tales comentou que evita consumir objetos e atividades que podem atrapalhar o seu desenvolvimento espiritual.

Hudson e Tales informam consumir "baladas" entre jovens com moderação, tais colocações corroboram com o posicionamento de Klein e Laczniak (2009) no sentido de que os consumidores católicos devem ser coerentes com os valores sociais da Igreja em suas práticas de consumo. Os jovens entrevistados mencionam que quando o fazem, procuram estar na companhia de jovens que professam a mesma religião, pois, estando em grupo, eles acreditam estar mais fortalecidos para evitar comportamento que julguem inadequados para jovens cristãos. Esse posicionamento vai ao encontro do ensinam Hirschman et al. (2010) e Solomon (2011), pois para Hirschman et al. (2010) a prática da fé leva os consumidores a buscar a conexão com o ser transcendente que geram sentimentos e valores que devem ser vividos na prática diária, enquanto Solomon (2011) destaca que as subculturas religiosas tendem a buscar uma certa homogeneidade nas escolhas de consumo com seu grupo de referência.

\section{Busca de Interação}

A participação no retiro também relevou o desejo de que o evento permitisse uma maior aproximação com Deus e com os irmãos. Alguns entrevistados mencionam que essa prática de consumo ajuda na interação com Deus e com o próximo. Segundo o teólogo Karl Rahner (1989), as atividades religiosas se revelam em eventos (tais como: retiros, shows, peregrinações, cerimônias etc.) ajudam na relação íntima de fé da pessoa com o ser transcendente de sua fé. Rahner (1989) discute sobre a busca de significado do homem pela vida, refletindo sobre o fato do homem "ser produto daquilo que não é", pois não é capaz de se dá a vida, tampouco de negociar sua finitude, apesar da pulsão pela eternidade. 0 autor conclui que a busca de relação com um ser transcendente remete a uma fé que expressa a existência de um ser maior do que si mesmo, capaz de lhe dá a vida e que lhe convida a viver em relacionamento. 
No grupo entrevistado que participou do retiro, jovens como Airton, Hudson, Carla, Leonardo e Tales expressaram claramente que a participação no EEJ era vista como uma forma de interagir com Deus. No mesmo sentido, Déia e Kelly entendem o retiro como uma oportunidade de se aproximarem de Deus. Para esse grupo de jovens, o retiro reflete uma experiência que permite uma interação com Deus, isto é, a busca de um relacionamento com o ser transcendental (Hirschman et al., 2010).

Segundo Bingemer (2009), crer tem muitos significados. Mas, no caso cristão, crer se trata de um ato pessoal que somente pode ser praticado por pessoas, pois está relacionado diretamente com a revelação de Deus ao homem e, portanto, diz respeito ao encontro e à confiança do homem para com Deus. Entre os entrevistados nessa pesquisa, é interessante mencionar alguns depoimentos que corroboram esse entendimento. Carla pontou que foi ao retiro para busca estar em oração para ter uma interação com Deus, buscando um acolhimento de Deus. Ela atualmente consome retiros ao menos duas vezes ao ano como uma prática de interação com Deus. Déia, por sua vez, informou que foi ao retiro do EEJ para alimentar o significado que a religião tem para sua vida, sobretudo manter o caminho de seu crescimento pessoal na fé mesmo diante das demandas do cotidiano intenso de uma estudante de medicina e realizando a residência médica. Segundo Hudson, a experiência do retiro em silêncio permite que ele se comunique melhor com Deus mesmo em momentos fora da oração, como por exemplo, por meio da contemplação da natureza.

Nesse sentido, fé também é uma expressão de experiência, na qual os indivíduos que crêem buscam interagir com o ser transcendental de sua fé para estabelecer uma relação que fundamenta sua própria vida (Bingemer, 2009). A fé como experiência mexe com os sentimentos e as emoções, sendo essa característica hedônica capaz de gerar efeitos em várias dimensões de seu comportamento, inclusive naquilo que diz respeito ao consumo (Araujo \& Rocha, 2016) e o uso de tempo livre com vivência de interação social e prática de lazer (Scott \& Harmon, 2016; Ryu \& Heo, 2018). Entre os entrevistados, Airton sublinhou que usa alguns objetos religiosos para se sentir mais ligado a Deus.
Alguns entrevistados também consumiram o retiro visando à interação com outras pessoas, como Isabela, Kelly, Leonardo e Tales. De acordo com Isabela, que é estrangeira, ir ao retiro seria uma oportunidade de interagir com pessoas que praticam a mesma fé e, assim, praticar o português. Leonardo consumiu o retiro com o intuito de fazer novas amizades, buscando conhecer pessoas espiritualizadas e com valores próximos ou similares aos seus. Bingemer (2009) sublinha que a fé, por ser uma experiência humana, não pode ser vivida isoladamente, mas em comunidade. Nesse sentido, é comum as pessoas desejarem compartilhar suas experiências e desejar interagir com outros que possuem a mesma fé.

Além disso, o desejo de se relacionar com outras pessoas que partilham os mesmos valores e crenças está ligado ao sentimento de pertencimento em um grupo social e cultural. Esse grupo pode formar um grupo de referência (Peter \& Olson, 2009; Solomon, 2011), no qual as pessoas compartilham significados e normas comportamentais, tendendo a gerar influências no consumo um dos outros. Em relação aos participantes do retiro, além das declarações espontâneas dos entrevistados nesse sentido, a funcionária da pastoral que ajudou na organização desta edição do EEJ (em entrevista aos autores) destacou sua percepção de que, entre as variadas motivações, os jovens que participam do retiro espiritual têm necessidade de fazer parte de um grupo de pessoas que partilham os mesmos interesses. Essa percepção aliada às informações trazidas pelos informantes corrobora para formação de um grupo de referência pela identificação dos pares, podendo gerar uma identidade coletiva de seus participantes.

\section{Construção e Reforço da Identidade}

De acordo com pesquisadores como Ahuvia (2005), Belk (1988) e Holt (2002), entre outros, o comportamento de consumo pode ser observado como um elemento para construção e reforço identitário dos indivíduos. Segundo Mansori (2012), a importância da religião está relacionada a um integrado sistema de crenças e práticas que interpõe o contexto social e a estrutura da vida daqueles que a praticam. Nesse contexto, Esso e Dibb (2004) vão destacar que a vida religiosa influi no comportamento de 
compra das pessoas, pois a religiosidade está relacionada à prática da fé e ao compromisso com o que os ideais, mantidos e praticados por um indivíduo. Neste estudo, observou-se que grande parte dos entrevistados consome objetos que refletem a identidade religiosa do subgrupo analisado, tais como escapulários, fitinhas ou terços. Estes objetos são comumente utilizados por integrantes da religião católica para ser reconhecido por indivíduos que compartilham da mesma estrutura significados, simbolizando externamente características de sua identidade e de seu "eu". Como colocado por Giddens (2002), as pessoas buscam reforçar o seu "eu" para construir aspectos de sua identidade.

A motivação para a participação do retiro do EEJ observadas nas informações colhidas com os jovens entrevistados permeia vários aspectos da dimensão simbólica que representou o consumo do evento para suas vidas. De acordo com as descobertas obtidas no estudo de Hirschman et al. (2010), a participação de eventos religiosos pode impulsionar o aumento dos gastos com objetos relacionados à religião, pois tal comportamento de consumo está relacionado com os valores e as crenças compartilhados pelo grupo religioso e remonta o desejo de expressar sua identificação com tais significados.

Esse fenômeno também foi mencionado entre os entrevistados que citaram o consumo recorrente de livros, CDs, camisas, fitinhas, terços, santos, anjos, bíblia. Outros citaram o consumo de eventos religiosos, tais como outros retiros, shows, cursos, cerimônias, peregrinações, encontros, festas religiosas etc., os quais destacam ser, além de um momento de integração com o grupo de referência, uma oportunidade de aprofundamento com os valores religiosos. Nesse sentido, o comportamento de consumo é capaz de revelar nuances da identidade religiosa dos participantes do grupo, fortemente impactada pela cultura na qual estes se inserem e pelas relações e práticas sociais nutridas ao longo do tempo. Esses achados vão ao encontro das contribuições trazidas por Minkler e Cosgel (2004), que observaram que o reforço da identidade religiosa é alimentado por meio de objetos e de participação de atividades ligadas à ritualística entre os praticantes da religião.
Para Mansori (2012), no contexto social, a importância da religião está relacionada ao que esta desperta a partir de um sistema de crença construída no meio social em que o indivíduo participa. No grupo de entrevistados foi possível observar que a ligação com a religião católica foi construída tanto pela influência familiar quanto pela formação educacional. Airton, Déia, Isabela, Kelly, Leonardo e Tácio declaram que seus pais praticavam a fé católica e isto foi importante para construção dos valores religiosos. Destacase que Isabela, Kelly, Leonardo e Déia, estudaram em colégio católico do ensino básico ao ensino médio. Um caso interessante foi o de Carla, que também teve influência religiosa dos pais, que eram espíritas kardecistas. Segundo ela, os pais ajudaram a construir a percepção que a religião torna a pessoa melhor, mas a deixaram livre para escolher a religião. Carla escolheu a religião católica porque foi a religião que a fez se sentir mais acolhida.

Segundo Wallendor e Reilly (1983), o reforço da identidade convive com a autenticidade e a diferença de contextos, pois os indivíduos convivem em diferentes contextos culturais, sejam entre amigos, familiares, colegas de trabalhos ou escolas, grupos esportivos, entre outros. Em tais contextos, o indivíduo pode tentar manter o estilo cultural de origem, pontuando aspectos de sua identidade, como os valores religiosos. Assim, nesses diferentes contextos, os indivíduos podem optar também por assumir outras identidades, uma vez que atualmente as pessoas podem assumir várias faces conforme a situação, apresentando sua identidade de forma multifacetada. Entre os entrevistados, alguns objetos pareciam remeter a demarcação de sua identidade.

As camisas, as fitinhas e os cordões eram expostos como forma de pontuar a identidade católica aos demais, reforçando os valores para os membros do grupo enquanto se afirmam para aqueles externos ao grupo de referência. Para eles, tais objetos pareciam ser parte do que Belk (1988) chama de eu-estendido, definindo uma extensão da própria identidade do consumidor. Esses produtos aparecem de forma tão essencial que precisam ser expostas aos outros, constituindo quase que uma parte de si ou, como colocado por Belk (1988) como parte de seu "eu".

A relação que o entrevistado Walter informou ter com o seu crucifixo mostrou-se 
instigante. Walter relacionou o crucifixo a própria marca de sua identidade religiosa. Por não pertencer originariamente a uma família católica, Walter foi construindo sua identidade católica depois de sua conversão ao catolicismo, o que se deu no final da juventude. Desta forma, "o uso" e "a exposição constante do uso" do crucifixo sugerem, ao mesmo tempo, a demarcação de sua identidade escolhida e o desejo de informar que a religião expressa no objeto compõe uma parte importante de si mesmo.

João também menciona ter objetos que ajudaram a construir e reforçar sua identidade católica. Apesar de criado em uma família católica, o encontro com a religião foi no início da idade adulta, após passar por sérios problemas pessoais. Ele informou ter encontrado apoio em um grupo jovem católico, com o qual se identificou e se tornou praticante até assumir lideranças no grupo. Entretanto, para João, um de seus objetos pessoais mais especiais é um escapulário de Nossa Senhora Aparecida. Ele procura sempre usar o objeto, muito embora este não fique exposto, ficando mantido sobre suas roupas.

Para João, o escapulário é identificado como parte de si e, nesse sentido, compõe o seu euestendido (Belk, 1988). Contudo, a relação de João com o escapulário se mostra muito mais profunda que apenas uma posse pessoal que compõe o seu "eu", mas se trata verdadeiramente de um objeto amado, tendo em vista a história do objeto com sua trajetória de vida (Ahuvia, 2005). De acordo com a experiência revelada pelo entrevistado, o desejo de aprendizado por atividades sagradas de sua religião remonta um objetivo intrínseco de construção da identidade a partir de sua experiência pessoal, gerando impacto em suas decisões de consumo conforme foi possível perceber em sua própria narrativa de vida (Ahuvia, 2005).

Airton destacou que usa objetos religiosos para se sentir mais ligado com Deus. Todavia, um consumo que considera expressar bem sua identidade religiosa foi o pedido de um serviço de tatuagem com a medalha de Santo Agostinho. Segundo ele, a tatuagem foi feita para expressar "personalidade e estilo próprio", sendo exposta em uma parte visível do corpo. 0 entrevistado informa que, pelo fato de ser músico rockeiro, é muito valorizado entre seus amigos fazer tatuagens, pois estimula o lado aventureiro do e atribui valor ao pertencimento ao subgrupo a que também faz parte, tal como foi observado na pesquisa de Schouten e McAlexander (1995). Porém, de acordo ele, o objetivo do informante em tatuar um símbolo católico foi mostrar que ele é um seguidor de Deus. Assim, a tatuagem tem o papel de refletir a sua identidade social que escolheu expressar, enquanto representa uma extensão de seu "eu" (Belk, 1988). Airton disse, ainda, que gosta de usar camisetas religiosas com frases de impacto, pois estas contribuem para relacionar a imagem de católico praticante de "personalidade" e a imagem de músico do gênero rock, articulando múltiplas facetas de sua identidade.

Tácio, durante a entrevista, definiu-se como um "católico tradicional e conservador". Ele vive a religião com muita intensidade no seu dia-adia, como um constante reforço da identidade católica. Diferente dos outros jovens entrevistados, o informante declarou ser contrário a todos as tentativas de modernização dos movimentos da Igreja. Tácio se dedica a um curso de latim e aulas de acólitos para poder participar da tradicional missa tridentina (rezada em latim), na qual o Padre precisa observar rubricas para rezar a missa no rito antigo.

Cristina, apesar de não querer se definir como religiosa, ao consumir o retiro buscava silêncio e reflexão, o que lhe permitiu experimentar uma nova forma de ver o mundo. A informante, que se considerava ateia, passou a buscar construir uma nova identidade, na qual se reconhece como uma pessoa de valores religiosos e crente em Deus. Fora do contexto religioso, Cristina integra um subgrupo que não se identifica com valores religiosos, razão pela assume ter dificuldade de considerar uma praticante de alguma religião, muito embora reconheça que agora se expressa como uma pessoa que busca ter espiritualidade, apresentando uma nova dimensão de sua identidade, escolhida por Cristina e que conflita com o seu círculo de amigos.

Percebe a existência de um certo conflito em relação a sua identidade social. Porém, como já sinalizado por Giddens (2002) quando discutiu o lugar da identidade social na modernidade, tais conflitos são inevitáveis no processo de construção de identidades, contudo é possível suavizar os conflitos gerados por meio de 
estratégias de interação social assumida pelo agente de acordo com o contexto.

Os achados nessa pesquisa contribuem para a determinação de que identidade individual perpassa por aquilo que o sujeito quer comunicar e mostrar aos outros, mas também é composto por valores, crenças e significados compartilhados por seu grupo (Peter \& Olson, 2009; Solomon, 2011). O consumo assume o papel de comunicar e mostrar algumas características de sua identidade aos demais. Desse modo, os aspectos simbólicos do consumo refletem imagens valorizadas pelo consumidor enquanto indivíduo, enquanto transmitem significado para o seu grupo social, ajudando a compor uma identidade coletiva (Jenkins, 2005; Minkler \& Cosgel, 2004).

\section{CONCLUSÕES}

Os resultados deste estudo, que investigou o comportamento de consumo de jovens da subcultura católica, sugerem que os objetos e as atividades religiosas consumidas têm um importante papel na construção individual e coletiva a partir dos significados atribuídos aos bens consumidos. Ao longo do trabalho, foram discutidos aspectos relevantes à temática, buscando clarificar os fatores que compõem o universo da análise. Observou-se uma forte presença da fé e das crenças como elementos influenciadores na construção da personalidade dos praticantes da religião estudada, como apontado por estudiosos do tema (Hirschman et al., 2010; Solomon, 2011).

0 retiro organizado pelos jesuítas para jovens tinha como principal objetivo promover valores religiosos da espiritualidade inaciana. Para isso, os jovens se retiravam de suas atividades cotidianas e procuravam exercitar a sua crença religiosa. 0 relato dos informantes no evento possibilitou observar que a participação na experiência religiosa teve motivações heterogêneas entre os jovens, mas verificou-se unanimidade entre os participantes quanto ao interesse de interação e aprofundamento com seus valores espirituais.

Uma das contribuições que surgiram neste estudo foi a sustentação já anunciada da influência da religião sobre as opções de consumo de produtos religiosos (terços, imagens, camisas, CDs, livros etc.) ou serviços religiosos (retiros, celebrações, eventos de jovens etc.), corroborando com os achados de estudos anteriores, tais como em Araujo e Tinoco (2015), Hirschman et al. (2010), Minkler e Cosgel (2004) e Wallendorf e Reilly (1983).

0 impacto deste consumo, como discutido ao longo do trabalho, é fruto de uma identidade que se cria e modifica ao longo do tempo (Ahuvia, 2005; Bourdieu, 2004; Giddens, 2002), auxiliando a moldar as preferências dos consumidores. Desta forma, os resultados do presente estudo sugerem que a religião contribui para o processo de formação das identidades daqueles que dela participam e, nesse sentido, a religião pode influenciar ativamente o consumidor durante o processo de aquisição de determinado objeto ou serviço religioso (Wallendorf \& Reilly, 1983). Com isso, o consumo de objetos sagrados pode também ser compreendido pelo conceito de euestendido desenvolvido por Belk (1988), demonstrando um maior ou menor papel na vida do indivíduo de acordo com o nível de engajamento nas práticas religiosas.

Além do aspecto individual, os entrevistados mencionaram o aspecto grupal do consumo religioso (Minkler \& Cosgel, 2004), demonstrando a construção de uma identidade católica coletiva relacionada ao subgrupo de jovens que praticam atividades da espiritualidade inaciana. Algumas atividades mencionadas pelos jovens esboçam a ideia identidade coletiva, como o próprio retiro inaciano, além de shows e cerimônia. Além disso, aspectos da identidade coletiva emergiram por meio de alguns objetos mencionados, os quais sinalizam aos outros o pertencimento à subcultura religiosa católica, dentre estes estão os mencionados usos de crucifixo, escapulário e até tatuagem.

As entrevistas seguem na direção de que as opções de aquisição de objetos ou atividades religiosas ocorrem de forma mais intensa do que se percebe ou se imagina. Nas entrevistas surgiram motivações de consumo referentes ao significado da experiência construída pela trajetória de vida (Ahuvia, 2005) e pelo comportamento de consumo compartilhado entre os jovens da religião estudada (Hirschman et al., 2010). Como se viu, o impacto da religião no consumo está intimamente relacionado à criação de significados construídos ao longo da vivência na religião (Minkler \& Cosgel, 2004), além da influência familiar e dos amigos que 
partilham da mesma crença religiosa, gerando grupos de referência (McFerran et al., 2010; Peter \& Olson, 2009; Solomon, 2011), que contribuem para as práticas de consumo dos indivíduos inseridos em seus respectivos contextos.

0 não consumo emergiu como um comportamento destacado pelos jovens como reflexo dos valores da religião e também pela influência exercida pelos demais integrantes do grupo da subcultura religiosa (Solomon, 2011). Os informantes mencionaram evitar consumo de produtos ou atividades que conflita com sua crença religiosa, bem como foi mencionado a importância do comportamento de consumo responsável e consciente para as pessoas religiosas, corroborando os valores destacados no estudo de Klein e Laczniak (2009) no que diz respeito ao consumo de pessoas católicas.

0 desenvolvimento da espiritualidade apareceu em todos os relatos. Entretanto alguns jovens mencionaram buscar maior interação com Deus, enquanto outros buscavam maior reflexão pessoal e interação também com outras pessoas que partilham valores similares aos seus. No estudo de Hirschman et al. (2010) também se verificou uma conexão entre a busca de interação com o transcendental e a prática de determinados comportamentos de consumo. Nesta pesquisa, essa conexão surge pelo consumo do próprio retiro inaciano, o qual foi identificado como uma oportunidade de relacionamento com Deus e de relacionamentos e construção de amizades com pessoas que compartilham a mesma crença religiosa.

A presente pesquisa possui limitações, pois se trata de um estudo de natureza qualitativa, não sendo possível a generalização empírica dos resultados. Apesar das limitações, o estudo apresenta contribuições relevantes ao conhecimento das características do grupo analisado. Desse modo, a pesquisa ajuda no aprofundamento das nuances do comportamento do consumidor inserido em subculturas religiosas. Pesquisas dessa natureza fornecem informações que permitem observar que as motivações de consumo podem ultrapassar o uso prático do objeto ou atividades consumidas, refletindo imagens valorizadas pelo consumidor e transmitindo significados para si mesmo e para o grupo social em que o indivíduo se insere. Finalmente, dada a relevância do tema aqui abordado, recomenda-se que outras pesquisas sejam desenvolvidas, visando à obtenção de um maior debate e do aprofundamento sobre as multifacetadas questões relacionadas ao comportamento e às práticas de consumo religioso.

\section{REFERÊNCIAS}

Aaker, D. A., Kumar, V., \& Day, G. S. (2001). Pesquisa de Marketing. São Paulo: Atlas.

Abdala, P. R. Z. (2010). Espiritualidade e Consumo: Relações e Temáticas de Pesquisa. XXXIV Encontro da Associação Nacional de PósGraduação em Administração - ANPAD. Anais... Rio de Janeiro: ANPAD.

Ahuvia, A. C. (2005). Beyond the extended self: loved objects and consumers' identity narratives. Journal of Consumer Research, 32(1), 171-184.

Ahuvia, A. C. (2008). If money doesn't make us happy, why do we act as if does? Journal of Economic Psychology, 29(4), 491-507.

Appadurai, A. (1990). Introduction: commodities and the politics of value. The Social Life of Things. Cambridge: University Press.

Araujo, F. F., Bitar, N. P., Santos, M. M. A. S., Baião, M. R., \& Silva, T. C. P. (2019). Experiências de Consumo no Samba: Um estudo sobre o processo de significação da Feijoada Portelense. Revista Alceu, 20(38), 142-163.

Araujo, F. F., \& Chauvel, M. A. (2012). Marketing de Cinema Francês no Brasil: Um estudo exploratório sobre as estratégias de promoção para o lançamento de filmes no mercado brasileiro. Revista FACEF Pesquisa Desenvolvimento e Gestão, 15(3), 298-315.

Araujo, F. F., \& Rocha, A. (2019). The redefining of later life through leisure: music and dance groups in Brazil. Leisure Studies, 38(5), 712727.

Araujo, F. F., \& Rocha, A. (2016). Significados Atribuídos ao Lazer na Terceira Idade: Observação Participante em Encontros Musicais. Podium: Sport, Leisure and Tourism Review, 5(2), 38-55.

Araujo, F. F., \& Tinoco, C. F. (2015). A Influência da Religião no Comportamento do Consumidor: Um estudo exploratório do consumo de produtos judaicos. Revista Alceu, 16(31), 3861.

Arnould, E., \& Thompson, C. (2005). Consumer Culture Theory (CCT): Twenty Years of Research. Journal of Consumer Research, 31(4), 868-882.

Arnould, E., \& Wallendorf, M. (1994). Marketoriented ethnography: interpretation building 
and marketing strategy formulation. Journal of Marketing Research, 31(4).

Bardin, L. (2011). Análise de conteúdo. Lisboa: Edições 70.

Barros, C. (2009). Na Internet todo mundo é feliz: sociabilidade e familiaridade no universo das camadas populares. In: Rocha, Angela da; Silva. Jorge Ferreira da. (Org.). Consumo na base da pirâmide: estudos brasileiros. Rio de Janeiro: Mauad, 97-112.

Belk, R. W. (1988). Possessions and the extended self. Journal of Consumer Research, 15(2), 139168.

Bingemer, M. C. L. (2009). A fé cristã na contemporaneidade: rumos e desafios. Perspectiva Teológica, 41, 345-374.

Breheny, M., \& Stephens, C. (2017). Spending time: the discursive construction of leisure in later life. Annals of Leisure Research, 20(1), 39-54.

Bourdieu, P. (1979). La Distinction: Critique sociale du jugement. Paris: Les Éditions de Minuit.

Bourdieu, P. (2004). O poder simbólico. Tradução de Fernando Tomaz. 7a․ ed. Rio de Janeiro: Bertrand Brasil.

Baudrillard, J. (1981). A Sociedade de Consumo. Lisboa: Edição 70.

Brakus, J. J., Schmitt, B. H., \& Zarantonello, L. (2009). Brand experience: What is it? How is it measured? Does it affect loyalty? Journal of Marketing, 73(1), 52-68.

Camelo, C. O., Thomé, K. M., \& Junqueira, A. M. R. (2018). Café e Valores de Consumo dos Brasileiros. Revista Brasileira de Marketing, 17(2), 220-236.

Dotson, M. J., \& Hyatt, E. M. (2000). Religious Symbols as Peripheral Cues in Advertising: A Replication of the Elaboration Likelihood Model. Journal of Business Research, 48, 63-68.

Elliot, R., \& Jankel-Elliot, N. (2003). Using ethnography in strategic consumer research. Qualitative Market Research, 6(4), 215-223.

Esso, N., \& Dibb, S. (2004). Religious influences on shopping behavior: an explanatory study. Journal of Marketing Management, 20, 683712.

Geertz, C. (1978). A interpretação das culturas. Rio de Janeiro, Zahar.

Giddens, A. (2002). Modernidade e Identidade. Rio de Janeiro: Jorge Zahar Ed.

Guido, G., Capestro, M., \& Peluso, A. M. (2007). Experiential analysis of consumer stimulation and motivational states in shopping experiences. International Journal of Market Research, 49(3).

Habermas, J. (2004). A Inclusão do Outro: Estudos da Teoria Política. Tradução: George Sperber \& Paulo A. Soethe, Milton Camargo Mota. 2a ed. São Paulo: Edições Loyola.
Hirschman, E. C., \& Holbrook, M. B. (1992). Postmodern consumer research: the study of consumption as text. California: Sage Publications.

Hirschman, E. C., Ruvio, A., \& Touzani, M. (2010). Breaking bread with Abraham's children: Christians, Jews and Muslims' holiday consumption in dominant, minority and diasporic communities. Journal of the Academy of Marketing Science, 39(3), 429-448.

Holt, D. B. (2002). Why Do Brands Cause Trouble? A Dialectical Theory of Consumer Culture and Branding. Journal of Consumer Research, 29(1), 70-90.

Holbrook, M. B., \& Hirschman, E. C. (1982). The experimental aspects of consumption: consumer fantasies, feelings, and fun. Journal of Consumer Research, 9(2), 132-140.

Iwasaki, Y. (2017). Contributions of leisure to "meaning-making" and its implications for leisure studies and services. Annals of Leisure Research, 20(4), 416-426.

Jenkins, R. (2005). Social Identity. 3a. ed. London: Routledge.

Joseph, D., \& Southcott, J. (2019). Meanings of leisure for older people: An Australian study of line dancing. Leisure Studies, 38(1), 74-87.

Klein, T. A., \& Laczniak, G. R. (2009). Applying Catholic Social Teachings to Ethical Issues in Marketing. Journal of Macromarketing, 29(3), 233-243.

Liechty, T., Genoe, M. R., \& Marston, H. R. (2017). Physically active leisure and the transition to retirement: The value of context. Annals of Leisure Research, 20(1), 23-38.

Lincoln, Y., \& Guba, E. (1985). Naturalistic Inquiry. London: Sage Publications.

Lin, M., \& Dong, E. (2018). Place construction and public space: Cantonese opera as leisure in the urban parks of Guangzhou, China. Leisure Studies, 37(2), 117-131.

Lipovetski, G. (2007). A Felicidade Paradoxal: Ensaios sobre a Sociedade de Hiperconsumo. São Paulo: Companhia das Letras.

Matsunobu, K. (2018). Music for life: A Japanese experience of spirituality, ageing and musical growth. Ageing \& Society, 38, 1100-1120.

Mansori, S. (2012). Impact of religion affiliation and religiosity on consumer innovativeness. World Applied Sciences Journal, 17(3), 301-307.

McCracken, G. (1988). Culture and Consumption: New approaches to the symbolic character of consumer goods and activities. Bloomington: Indiana Press University.

McFerran, B., Dahl, D. W., Fitzsimons, G. J., \& Morales, A. C. (2010). I'll have What She's Having: Effects Social Influence and Body Type on the 
Food Choices of Others. Journal of Consumer Research, 36(1).

Minkler, L., \& Cosgel, M. M. (2004). Religious Identity and Consumption. Economics Working Papers. Connecticut: Berkeley Electronic Press.

Oliveira, R. C. (2006). "Olhar, Ouvir, Escrever". O Trabalho do Antropólogo. São Paulo: Ed. UNESP, 19-26.

Peter, J. P., \& Olson, J. C. (2009). Comportamento do consumidor e estratégia de marketing. São Paulo: McGraw-Hill.

Picanço, M.N.B. (2017). Comida, Consumo e Identidade: Notas etnográficas por entre os processos migratórios da mandioca do contexto brasileiro paraense ao contexto europeu. Mosaico, 8(13), 203-221.

Rahner, K. (1989). Curso Fundamental da Fé: Introdução ao Conceito de Cristianismo. São Paulo: Paulinas.

Rocha, E. (2006). Comunicação, consumo e espaço urbano: novas sensibilidades nas culturas jovens. Rio de Janeiro: Mauad.

Ryu, J., \& Heo, J. (2018). Relationships between leisure activities types and well-being in older adults. Leisure Studies, 37(3), 331-342.

Sahlins, M. (1979). Cultura e razão prática. Rio de Janeiro, Zahar.

Sandicki, Ö. \& Ger, G. (2010). Veiling in style: how does a stigmatized practice become fashionable? Journal of Consumer Research, $37(1)$.

Schouten, J. W., \& McAlexander, J. H. (1995). Subcultures of Consumption: An ethnography of the new bikers. Journal of Consumer Research, 22, 43-61.

Seidman, I. (1998). Interviewing as qualitative research. New York: Teachers College Press.

Silva-Lacerda, J., Vasconcelos, J., Silva, J., \& Abreu, N. (2016). "Antropocêntricos ou Ecocêntricos?":
As Motivações dos Consumidores para a Compra de Alimentos Orgânicos em uma Feira de Recife-PE. Gestão e Sociedade, 10(25), 1255-1273.

Silveira, E. S. (2011). Festa Católico-Carismática e Pentecostal: Consumo e Estética na Religiosidade Contemporânea. Revista Brasileira de História das Religiões. 3(9).

Scott, D., \& Harmon, J. (2016). Extended leisure experiences: A sociological conceptualization. Leisure Sciences, 38(5), 482-488.

Solomon, M. (2011). O comportamento do consumidor: comprando, possuindo e sendo. Trad. Lene Belon Ribeiro. $9^{\circ}$. ed. Porto Alegre: Bookman.

Strauss, A. \& Corbin, J. (2008). Pesquisa qualitativa: técnicas e procedimentos para o desenvolvimento de teoria fundamentada. (2 $2^{\underline{a}}$ Ed). Porto Alegre: Artmed.

Vergara, S. C., \& Caldas, M. (2005). Paradigma Interpretacionista: a Busca da Superação do Objetivismo Funcionalista nos Anos 1980 e 1990. In: Caldas, M.P.; \& Bertero, C.O. Teoria das Organizações. Série RAE - Clássicos. São Paulo: Atlas.

Thompson, C. J. (1997). Interpreting Consumers: A hermeneutical framework for deriving marketing insights from the texts of consumers' consumption stories. Journal of Marketing Research, 34(1), 438-455.

Tureta, C., \& Alcadipani, R. (2011). Entre o Observador e o Integrante da Escola de Samba: os Não-Humanos e as Transformaç̧ões Durante uma Pesquisa de Campo. Revista de Administração Contemporânea, 15(2), 71-78.

Wallendorf, M., \& Reilly, M. D. (1983). Ethnic migration, assimilation and consumption. Journal of Consumer Research, 10(3), 292-302.

\title{
Religious Subcultures of Consumption: an ethnography of young Catholics in the practice of the Spiritual Exercises
}

\begin{abstract}
The aim of this paper was to identify the impact of religion on consumer choices, seeking to understand its influence of the meaning assigned consumer on the construction of individual and collective identity of such young. We limit the catholic consumption culture to products and activities for religious use, such as retreats, ritual objects, symbolic objects and instruction objects, restricting the analysis and avoiding epistemological deadlocks. We used the ethnographic method of participant observation in a Catholic retreat dedicated to the practice of the Spiritual Exercises developed by St. Ignatius, founded the religious order Society of Jesus, and also we conducted in-depth interviews with event organizers and participants. The results indicate four main trends related: symbolism and meaning, construction and reinforcement of identity, not consumption; seeking interaction. The study contributes to the
\end{abstract}


existing knowledge regarding the relationship between consumer behavior and religious practices, besides to opening new research perspectives.

Keywords: Consumer Behavior, Religious Consumption Practices, Social Identities. 